\title{
Diverse Career Possibilities AND A Broad OCEANOGRAPHY CURRICULUM
}

\author{
By Jonathan H. Sharp
}

$A$ TOS last April, there was a panel discussion titled, "Education in Ocean Sciences: Careers and Curricula". It was a stimulating and exciting forum and has led to this new regular column in Oceanography. Although curriculum has been debated in oceanographic institutions, a logical twist at the TOS meeting was to link the curriculum discussion with one on careers and then to open the scope of the career discussion.

The topic of careers in marine sciences is treated in a broader than traditional sense in the recent TOS publication ("Careers in Oceanography and Marine Related Fields"). Alternative careers for aquatic scientists were discussed at the American Society of Limnology and Oceanography meeting this summer and in a recent article on undergraduate ocean education in Sea Technology (September 1995). The American Geophysical Union Committee on Education, in evaluating future employment of geophysicists (EOS, Sept. 19, 1995), suggests more diverse career paths in industry, government, and teaching at all levels as well as the traditional academic research. Related to the linkage of curriculum and careers is the recent NAS report "Reshaping the Graduate Education of Scientists and Engineers."

The pages of Oceanography previously have carried debate on the critical element of "breadth" in curriculum with the article on physical oceanography education by Pedlosky (Vol. 5, No. 2, 1992) and letters by Korgen and Leipper (Vol. 5, No. 3, 1992) and Tomczak (Vol. 6. No. 2, 1993). Pedlosky, in arguing against too much breadth in formal education, "that is as paralyzing to creative

Jonathan H. Sharp, Graduate College of Marine Studies, University of Delaware, Lewes, DE 19958 USA. research as the traditional 'all branches of oceanography" program," addresses only the single career goal of academic research. He includes the statement in his article of, "the successful graduates go almost without exception into an academic or government research career." Many argue for a broader exposure than that advocated by Pedlosky; partially including Leipper and Tomczak. The delightful commentary by Wyrtki (Vol. 3, No. 1, 1990) on his own education, extols the virtue of breadth. It is also necessary to consider alternate careers.

Traditionally, we have tried to give breadth to the curriculum by offering core courses (usually four) in the subdisciplines of oceanography. In recent years, the undergraduate texts in oceanography have evolved from the traditional subdisciplines to reflect the multidisciplinary nature of the field. I have taught a chemical oceanography core course for many years and have been involved in attempts to better integrate the core courses in my own institution; I have also taught an undergraduate introductory oceanography course. I am not convinced that it is necessary to have four distinct core courses. However, it is critical to expose oceanography students to the breadth traditionally covered by all of the areas of the core courses.

My argument is that all marine science students should be exposed to breadth in their curricula such as was traditionally used in oceanography. At least three different career paths dictate such a broad background. These three include pure independent research, research and teaching in an academic institution, and nonresearch activities.

\section{The Exclusively Research Path}

There will continue to be some positions for those whose entire career is spent in doing only research. Thus we will need to continue to train some Ph.D. oceanographers exclusively for research careers. However, some of the best researchers have good breadth in their training. The idea that one can obtain depth in training only by avoiding taking the basic core courses in oceanography is not correct. Our average M.S. students take two to three years for their degrees and Ph.D. students take an additional three or more years. There is sufficient time in such tenure for a few broadening core courses. Perhaps the need for formal advanced specialty courses that compete for time with core courses might be better fulfilled by independent study or individual background reading in pursuit of the actual research project.

Breadth is critical to creative research. Many a student forced to take a core course outside of her/his specialty field discovers ideas that eventually influence later research pursuits. Often an individual who goes into great depth in a narrow field becomes myopic and is not as able as one with a broader background to think of new ways to solve problems.

If oceanography is multidisciplinary, oceanographers should master multiple disciplines. In the early part of this century, our oceanographic forerunners were truly multidisciplinary; we should aspire to that designation. It should be possible to treat more than one subdiscipline in sufficient depth to pursue cutting-edge research. In multi-investigator research, one should have sufficient knowledge of the specialty field of the other scientists involved to collaborate with understanding of each other's specialties. Some of the best interdisciplinary research is carried out by investigators of different specialties working together. This only happens when they can speak each other's languages.

\section{The Academic Institution Path}

Many Ph.D. graduates who pursue a research career do so in an environment 
where teaching is also an integral part of the job. There are sufficient general texts in oceanography ranging from high school to advanced undergraduate levels to demonstrate that this is a distinct discipline. Just as a physicist in an academic department may be called upon to teach introductory physics and a biologist to teach introductory biology, an oceanographer should be able to teach introductory oceanography. Additionally, there have been recent job announcements in geology and chemistry departments for marine geologists or chemists who can include general oceanography as part of the teaching load. There is a need for oceanographers who can teach the general field of oceanography in oceanography departments as well as in other science departments. A Ph.D. oceanographer should not be considered competent to teach the general course in his/her field if $s /$ he has not had the broad training provided by traditional core courses.

Again, as with the exclusively research career path, one gains new insight and new approaches to solving problems with exposure outside one's narrow specialty area. Teaching general oceanography can force one to rethink the approach to one's specialty research area and to conceive new ideas.

\section{The Nonresearch Path}

Some of us in the academic oceanographic field view our educational responsibility as the production of more of ourselves. Yet, there are not enough jobs for our students. If we are exclusively training more research faculty for academic institutions and research laboratories, then probably each of us should produce only one student in our career unless we are expecting an expanding field. Actually, many of our recent students have gone into federal agencies in positions not really describable as "independent research"; into regional, state, or local government agencies in research, monitoring, or resource management positions; into small college or university positions where primary responsibilities are for undergraduate or nonoceanographic teaching; into primary and secondary education positions; and into a variety of other places. We should treat all of these careers as worthy and desired goals for our best students.

Broad oceanographic training is graduate-level applied science training. It should include in-depth experience with fundamental research. The distinction is made here between applied science and applied research. The complexities of the environmental problems that we face today require multidisciplinary knowledge and understanding in a much larger portion of our population than just the scientific research community. Decisionmakers and resource managers in federal, state, and regional governments should have the benefit of recognizing the complexity and interrelatedness of environmental problems and the value of real research and effective monitoring. An M.S. or Ph.D. graduate with broad oceanographic training and research experience can bring a great deal to such a government position. We have spent fortunes in recent decades on worthless compliance monitoring and regulationbased studies while resource managers made decisions on the basis of laws rather than understanding of the environment. In the atmosphere of the environmental damage of the $1960 \mathrm{~s}$, a draconian approach worked, but more knowledgeable resource management is required today.

Our graduates should enter into political and government positions where they will influence resource management. They should go to undergraduate teaching institutions where nonscience students might have an oceanography course as their only exposure to environmental problems. Our graduates should also be in primary and secondary education positions where they can expose young minds to the multidisciplinary nature of science education. Today, many students graduate from high school with the idea that only biology is a natural science whereas physics, chemistry, and advanced mathematics are physical sciences-more theoretical and primarily applied to human endeavors. With broad-based multidisciplinary oceanography graduates in primary, secondary, and undergraduate education and in natural resource management and other government positions, there may be greater public recognition that the ocean, the terrestrial environment, and the atmosphere must be approached in a multidisciplinary natural science fashion.

\section{Do We Need to Redirect Our Graduate Education?}

As may be obvious from the last paragraph, I do not feel that we need to vastly change oceanographic education. Instead, I feel that we should reflect a bit on past practices, refine a bit, but then stick to the multidisciplinary approach of oceanography. It is interesting to dig out Sverdrup, Johnson, and Fleming's The Oceans and ask if we should not continue the rigor and breadth of that earlier oceanography bible.

The previously mentioned NAS report contains the statement, "A world of work that has become more interdisciplinary, collaborative, and global requires that we produce young people who are adaptable and flexible, as well as technically proficient". That describes what we have been trying to accomplish in oceanographic education.

The NAS report's conclusion that those in science and engineering education need to rethink the career options of their students is correct. The need for more versatile students who can do other than academic research is correctly described. However, we should recognize that our graduates are already versatile with their multidisciplinary training and are already pursuing careers other than only academic research. Some of the recommendations of the NAS report are consistent with what we are already doing. Maybe physics, chemistry, and even biology and geology departments should train fewer Ph.D.s, and instead direct more of their best undergraduates into oceanography. We could continue to educate the same number of students as in the present but with a more diverse pool of applicants (especially more chemists, physicists, and mathematicians) who are well trained in pure science undergraduate fields. At the same time, we must be more open in our evaluations of what career paths are valid and important for our graduates to pursue. 